\title{
Behavioural responses to cold thermal discomfort
}

\section{Stephanie Gauthier and David Shipworth}

UCL Energy Institute, University College London, Central House, 14 Upper Woburn Place, LondonWC1H ONN,UK

E-mail: s.gauthier@ucl.ac.uk and d.shipworth@ucl.ac.uk

Heating energy demand in buildings depends in part on occupants' behavioural responses to thermal discomfort during the heating season. The understanding of this has become one of the priorities in the quest to reduce energy demand.

Thermal comfort models have long been associated with occupants' behaviour by predicting their state of thermal comfort or rather discomfort. These assumed that occupants would act upon their level of discomfort through three types of response: mechanisms of thermoregulation, psychological adaptation and behavioural responses. Little research has focused on the behavioural aspect. One of the key challenges is to gather accurate measurements while using discreet, sensor-based, observation methods in order to have minimum impact on occupants' behaviour. To address these issues, a mixed-methods approach is introduced that enables the establishment of a three-part framework for mapping behaviour responses to cold sensations: (1) increasing clothing insulation level; (2) increasing operative temperature by turning the heating system on/up; and (3) increasing the frequency, duration and/or amplitude of localized behaviour responses such as warm drink intake or changing rooms. Drawing on this framework, an extended model of thermal discomfort response is introduced that incorporates a wider range of observed behaviours.

Keywords: adaptive behaviour, comfort provision, metabolic rate, monitoring, occupant surveys, thermal comfort, thermal insulation of clothing 


\section{Introduction}

In the UK during the heating season, indoor temperature is one of the strongest determinants of the energy used in buildings (Hughes, Palmer, Cheng, \& Shipworth, 2013). In 2012, the domestic sector was responsible for approximately $31 \%$ of the total energy consumption in the UK (DECC, 2013a). Space heating alone accounted for $62 \%$ of the UK's household energy consumption in 2011 (DECC, 2013b). Therefore, strategies aiming to reduce domestic heating consumption can make a significant contribution towards the UK's national $\mathrm{CO}_{2}$ emissions reduction commitments (UK Parliament, 2008). As a result, how people respond to cold thermal discomfort plays a key role in the quest to reduce energy use.

While there are many theoretical approaches to understanding thermal comfort, and even more anthropological, sociological, psychological and economic theories about the ways occupants act to achieve it, there are only two primary models of thermal comfort that impact on national and international standards in the field. It is through embodiment of these comfort models in standards, and through reflection of those in building energy models, that thermal comfort research impacts most immediately and substantively on building design, and hence on energy demand in buildings. Due to their central role, these standards are reviewed below in more detail.

There are currently two primary models to assess human thermal comfort: adaptive and predictive models - ISO 7730:2005 (ISO, 2005); ASHRAE 55:2013 (American Society of Heating, Refrigerating and Air Conditioning Engineers (ASHRAE), 2013); and EN 15251:2007 (CEN, 2007). Adaptive models are derived from empirical studies and assume that occupants' preferred indoor operative temperature varies with external air temperature, and that this relationship is linear. As the only independent variable is external air temperature, this model implies that this environmental variable is the main 
influencing factor in determining occupants' level of thermal discomfort. It should be noted, however, that in the context of cold thermal discomfort during the UK winter heating season, where running mean outdoor air dry-bulb temperatures are routinely below $15^{\circ} \mathrm{C}$, that the adaptive approach is not deemed applicable in such temperatures. The second type of thermal comfort models are based on physical and physiological principles and have six input variables: ambient air temperature $\left(\mathrm{T}_{\mathrm{a}}\right)$; mean radiant temperature $\left(\mathrm{T}_{\mathrm{r}}\right)$; relative humidity $(\mathrm{RH})$; relative air velocity $\left(\mathrm{v}_{\mathrm{a}}\right)$; metabolic rate $(\mathrm{M})$; and clothing insulation ( $\mathrm{I}_{\mathrm{cl}}$ ) (ISO 7730:2005, Annex D; ISO, 2005). In order to determine where the priorities for refining the accuracy and precision of input variables should be focused, Gauthier and Shipworth (2012) reviewed the current standard predictive model (ISO 7730:2005) and reported on an evaluation of global sensitivity of this model. This analysis provides an insight of how the model's dependent variables respond to changes in the independent variables and allows for a determination to be made as to which independent variables have the greatest and the least influence on the dependent variables. Interestingly, the predictive model appears to be most sensitive to the personal variables, i.e. metabolic rate $(\mathrm{M})$ and thermal insulation of clothing $\left(\mathrm{I}_{\mathrm{cl}}\right)$, therefore accuracy and precision of the model's comfort assessments is most heavily dependent on the accuracy and precision of measurement of these two variables. In field studies, however, these personal variables are often estimated with a great degree of uncertainty, and in building simulation studies these variables are given constant values as a function of the seasons and the building or room types. Considering that these personal variables are the most influential variables, this high level of uncertainty will most likely reduce the accuracy, and certainly reduce the precision, of the results of the models. With regard to behavioural adaptation, the six predictive model independent variables will be directly affected by changes in behaviour, in particular clothing and 
activity level. Therefore, it is important to develop a method to monitor the variability of these two variables.

The research presented in this paper aims to explore the variability of people's responses to cold thermal discomfort in a dwelling, in particular monitored, observed and reported behavioural responses. In order to address this complex issue, it was important to develop a mixed-method approach that drew on subjective and objective methods. Fundamentally, it relies on a longitudinal analysis of participants and their behaviours in a free-living environment. Based on a review of current methods used to assess occupants' thermal comfort, emerging methods in neuropsychological research (Silva, Pinho, Macedo, \& Moulin, 2013) and the results of semi-structured interviews, two aims were determined for the research presented in this paper:

- To estimate metabolic rate $(\mathrm{M})$ and clothing insulation $\left(\mathrm{I}_{\mathrm{cl}}\right)$ values as objective, quantitative and continuous data. Data analysis of the results from mixedmethod framework allowed empirical probability distributions of $\mathrm{M}$ and $\mathrm{I}_{\mathrm{cl}}$ values to be generated.

- To map a rich picture over a continuous timeframe of people's variability in daily activity in order to capture and categorize participants' behavior responses to thermal discomfort.

Finally, the mixed methods employed, and the findings of this study, enable the introduction of an extended model of thermal discomfort responses that incorporates a wider range of observed behaviours. This model considers the heat flow around the body with four components and the resistances in between. Millman's theorem is then applied as a method to estimate the terms within the model. 


\section{Literature review}

Thermal comfort refers to physical, psychological or psychosocial issues where peoples' opinions validate their state of comfort or discomfort. As described by Brager and de Dear (1998), people may adapt to their state of thermal discomfort through three types of mechanisms: physiological, psychological and behavioural adaptation. By applying analytic hierarchy process (AHP) to case studies conducted in the UK and China, Liu, Yao, and McCloy (2012) have developed a method to determine the significance of these three responses in the adaptation process. In the UK, physiological adaptation had the highest weighting factor (51\%), while the importance of psychological adaptation (26\%) was regarded slightly higher than psychological behavioural adaptation (24\%). Although these results are based on the subjective assessments of 41 experts and academics, they are suggestive of the relative importance of the respective forms of adaptation. Focusing on behavioural adaptation, people may use this form of response to thermal discomfort to cope with their thermal environment, through either deliberative actions or habituated behaviours. In their home it is assumed that people have access to a wide range of adaptive opportunities. Occupants may choose to manage their thermal comfort level using different adaptive opportunities, including (Heerwagen \& Diamond, 1992; Brager \& de Dear, 1998; Karjalainen, 2009; Hwang \& Chen, 2010):

- controlling heat sources by reducing/increasing temperature and radiant heat load; by adjusting thermostats or using local heaters

- shielding the source of cold by using 'barriers' such as curtains on windows

- controlling the air movement by reducing/increasing draught, by closing/opening window or doors or by using fans 
- changing location within a room or the house; each activity might have a bestsuited location to perform a task and be thermally comfortable

- changing level and type of activity

- changing food and liquid intake, e.g. by having warm drinks or food

- adjusting clothing insulation level; multiple layers of clothing enable one to make adjustments based on one's own subjective thermal sensation

- using localized behaviour adaptation, e.g. a hot water bottle

The review by Brager and de Dear (1998) highlights these behavioural adaptations may be undertaken consciously or unconsciously by the occupants. These may be personal, technological or cultural adaptive actions, habituated behaviour and practices, and may be influenced by the climate, socio-economic constraints, other occupants, future task(s) and the physical context, including the level of control a person has over the surrounding environment. In their home, occupants may have control over a large range of options, from moving around to closing windows and turning on the heating system. Research has shown that occupants in naturally ventilated buildings are comfortable over a wider range of temperatures than occupants in mechanically ventilated buildings. One explanation for this lies in occupants' levels of control over their environment, with those in naturally ventilated buildings having the adaptive opportunity to open windows, whilst those in mechanically ventilated buildings do not. Studies investigating how personal control of windows influences occupants' thermal comfort include de Dear, Brager, and Cooper (1997) and Brager, Paliaga, and de Dear (2004). These studies show that thermal preference may be based not only on physiological and physical factors but also on the degrees of control over the thermal system. Other studies show similar findings with use of control, spatial variation, temporal variation, clothing and activity level (Baker \& Standeven, 1995). In particular, clothing level may 
be both a potential cause of thermal discomfort as well as a control strategy. An occupant may choose to add layers of clothing if feeling cold or remove them if warm (Baker \& Standeven, 1997; de Carli et al., 2007; Morgan \& de Dear, 2003). The level of clothing insulation may be reduced by the increase of ambient temperature, of air velocity and/or of activity level.

In the current standard predictive model ISO7730:2005 (ISO, 2005), the six inputs will be affected by behavioural adaptation, e.g. metabolic rate (M) will increase if one is more active, clothing insulation level $\left(\mathrm{I}_{\mathrm{cl}}\right)$ will increase if one puts on a jumper, and ambient air temperature $\left(\mathrm{T}_{\mathrm{a}}\right)$ might decrease when changing room. However, the localized actions are not accounted for in this model as these might not be part of physiological or physical changes but a psychological adaptation. The study by Baker and Standeven (1994) aimed to identify these adaptive processes and to incorporate the findings into a predictive comfort model. However, the results from observations and questionnaires only gathered information on the use of clothing and activity and did not address behavioural adaptation.

Approaches adopted to date for the analysis of occupant behavioural adaptation to cold thermal discomfort in homes (as opposed to laboratory environments) have predominantly employed ethnographic or sociological methods, relying on participant observation or self reported data. As listed above, these have provided a rich and valuable picture of the range of adaptive responses employed by people in homes. Such approaches are also subject to two important forms of bias. Observational studies are subject to Hawthorne effects, are difficult to scale to larger sample sizes and introduce inter-observer biases when doing so. Sociological studies using interviews, focus groups and other methods of eliciting self-reported data are subject to poor subject recall of habituated behaviours, as well as forms of social desirability response bias. Whilst data 
on the forms of adaptive responses are necessary, this information is also insufficient in that it does not provide reliable data on the frequency with which different adaptive responses occur. Frequency data are important for the construction of statistical models and for understanding the comparative importance of different adaptive responses. Future studies should therefore aim to capture both the variety of adaptive responses known to occur, but importantly to quantify the frequency with which they occur.

\section{Methods}

To address these issues, this paper introduces a mixed method framework drawn from thermal comfort research and emerging methods in psychology. First, a pilot study was carried out in the south-east of England during the winter of 2011. The objective of the pilot study was to evaluate the data collection and analysis methods to be deployed in the main study. The sampling frame was based on previous thermal comfort studies, and included:

- Socio-demographic characteristics. Participants' genders and participants' patterns of use of the home, in particular their employment status (working fulltime, part-time, retired, registered unemployed and full-time student) and tenure status (own or rent the property). A study by Karjalainen (2007) shows significant gender differences in thermal perception, temperature preference and use of thermostats, whereas patterns of use have shown to have an influence on heating demand (Hughes et al., 2013).

- Dwelling characteristics. Built forms, ages, heating systems and energy efficiency ratings (from A to $\mathrm{G}$ ). These variables are particularly influential to space heating demand (Hughes et al., 2013). 

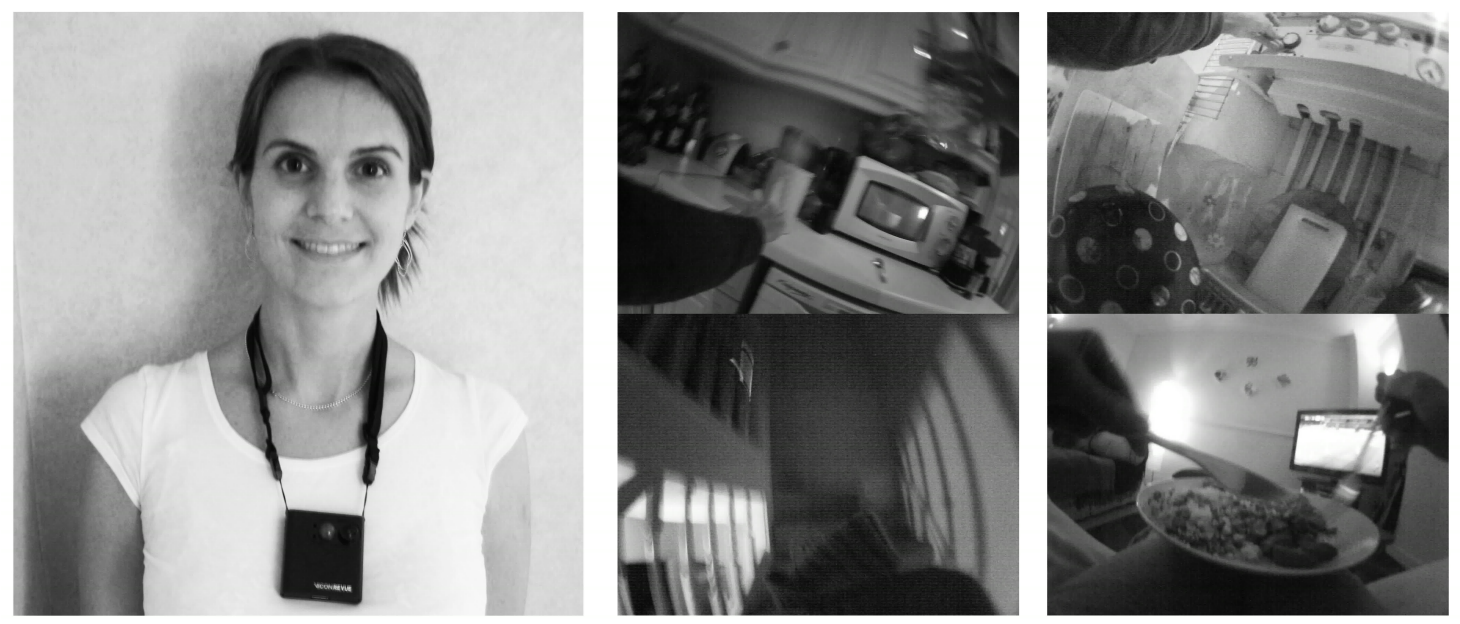

Figure 1 Participant wearing a SenseCam and a sample of four pictures

In the pilot study, 11 participants living in 10 dwellings were each monitored over a period of three consecutive days, two weekdays and one weekend day using wearable sensor (SenseCam) and indoor environmental sensors (HOBO U12-012). One of the key issues in comfort research is the development of methods to gather accurate measurements while using discreet observatory methods in order to have minimum impact on people's behaviour (thus minimizing Hawthorne effects). In this study, an automated diary called a SenseCam (Hodges et al., 2006) was used to log occupants' responses systematically (Figure 1). Of similar size to a smartphone, this recording device takes photographs when triggered manually by the user or automatically by a timer or by changes in sensor readings. It incorporates a temperature sensor (Nat Semi LM75), a light intensity sensor (TAOS TCS230), a passive infrared detector (Seiko SKPMS401), a tri-axis accelerometer (Kionix KXP84) and a magnetometer. Calibration tests were carried out with the HOBOs and the SenseCams in climate chamber prior to the studies; results show that for both types of temperature sensors the measurement errors are within the sensors' accuracy range $\left(\mathrm{HOBO} \pm 0.35^{\circ} \mathrm{C}\right.$, SenseCam $\left.\pm 2^{\circ} \mathrm{C}\right)$. HOBOs were within ISO 7726:2001's (ISO, 2001a) required level of accuracy of 
$\pm 0.5^{\circ} \mathrm{C}$ for air temperature, however the SenseCam did not met this requirement.

Unfortunately no other instrument was available at the time of study that combined the range of sensors required. The SenseCam also provides a visual diary of participants' whereabouts in their home and a record of measurements taken by each sensor. Through the three monitoring days, around 3200 images were generated automatically for each participant. The study ran over six weeks and was followed by a focus group, which was attended by nine of the 11 participants. Using content analysis, the focus group's transcripts revealed that the most frequently reported responses to thermal discomfort for the sample group were: (1) interacting with the heating system via thermostatic radiator valves (TRVs), room thermostat or programmers $(44 \%),(2)$ putting on an item of clothing (38\%), and (3) food or drink intake (12\%). Although this focus group revealed an understanding of what people believe they do when feeling cold at home, focus groups as a method are known to be subject to two potential biasing effects. Firstly they are subject to 'group effects' where participants' may be prone to expressing culturally expected views rather than individual ones. Secondly, they are subject to 'moderator effects' where participants feel the need to please the moderator (Bryman, 2004).

The pilot also tested the feasibility of data collection and analysis using the SenseCam visual diary. The visual diary images were first analysed using a manual segmentation approach. Each image was labelled using five categories including: (1) image number; (2) when the image was taken; (3) where the image was taken; (4) clothing; and (5) activity levels. $\mathrm{I}_{\mathrm{cl}}$ and $\mathrm{M}$ were both estimated using observation of the images from the visual diary and ISO 7730:2005, Annexes B and C respectively (ISO, 2005). It was found that the wide-angle lens of the camera on the SenseCam allowed for identification of clothing worn on the lap (when seated), arms and legs. While the camera is directed 
away from the body, images of the arms and lap were captured that allowed for identification of changes in clothing. In conjunction with accelerometer-triggered photographs when clothing was being changed, and the light sensor identifying when the SenseCam was covered by clothing, reliable identification of clothing adaptations was achievable.

Activity events were determined in the pilot study using observation of the images. For each participant, all images were sequentially visually inspected. Adjacent images were compared; if a change in one of the five categories occurred, then a new 'event' was identified. Pilot study results showed that the most frequently observed event was participant changing activity levels, which lead to variation in metabolic rate. For example, if a participant was 'seated and relaxed', then according to ISO 7730:2005, Annex B (ISO, 2005), a metabolic rate of 1 met was assigned for the duration of this activity. Having determined the six independent variables for the predictive model, predictive mean vote (PMV) was plotted for all participants throughout their individual monitoring period. Overall, the mean PMV for all participants was $-0.9 \pm 0.5$. The analysis then focused on the cause for an increase in PMV for each participant during the monitoring. For example, a participant may chose to move around within the same space, move to another space or leave a space and return. Results of this analysis showed that changing location was the most frequently observed cause for an increase in PMV. This contrasted with the findings from the focus group that identified interacting with the heating system as the most common response to thermal discomfort. Here the observed increase in PMV with reducing temperatures has been interpreted as a cold thermal discomfort response, however as participants were not asked to keep a diary of their thermal responses (due to concerns over potential Hawthorne effects) and 
no independent observations were made, additional research is needed to corroborate this interpretation.

With regard to the sampling criteria described above, there was no statistically significant difference between genders, employment status, tenure status or between dwellings' energy efficiency ratings (Kruskal-Wallis rank sum test, $p>0.05$ ). Lessons learnt from the pilot study significantly impacted on the conduct of the main study. As focus group findings could be subject to considerable 'group effects' with respect to reported thermal discomfort responses, individual elicitation of discomfort responses was the method selected in the final study. With respect to segmentation, although providing interesting insights, this data analysis approach deployed in the pilot proved to be time consuming and was thought likely to introduce 'coder bias' in the observation through the subjective assessment of the event. For this reason, automatic segmentation was deployed in the main study. This is described under 'Observed responses to thermal discomfort' below.

Incorporating lessons learnt from the pilot study, a larger main study was carried out in the south-east of England during the winter of 2013 (January- March and OctoberDecember). Monitored external temperatures were below the degree-day threshold of $15.5^{\circ} \mathrm{C}$ for $99.6 \%$ of the recording period, and therefore considered low enough to require space heating according to Chartered Institution of Building Services Engineers (CIBSE) TM41 (2006). The sampling frame was defined by the three physiological attributes prescribed by ISO 8996:2004, Annex C (ISO, 2004), as gender, age and weight. These variables have a direct influence on the estimation of metabolic rate, which is the most influential variable in the predictive model (Gauthier \& Shipworth, 2012). The sample frame was populated across combinations of these three attributes using a mixture of convenience and snowball sampling (Figure 2). Within the sample 


\begin{tabular}{|c|c|c|c|c|c|}
\hline \multirow{2}{*}{ Age (years) } & \multicolumn{5}{|c|}{ Weight $(\mathrm{kg})$} \\
\hline & $50 \mathrm{~kg}$ & $60 \mathrm{~kg}$ & $70 \mathrm{~kg}$ & $80 \mathrm{~kg}$ & $90 \mathrm{~kg}$ \\
\hline \multicolumn{6}{|l|}{ Women } \\
\hline 20 & P01 & & & & \\
\hline 30 & & P02, P09 & P07 & & \\
\hline 40 & & $\mathrm{P} 03, \mathrm{P} 10, \mathrm{P} 17$ & & & \\
\hline 50 & & & & & \\
\hline 60 & P14 & & P19 & & P16 \\
\hline \multicolumn{6}{|l|}{ Men } \\
\hline 20 & & P05 & P04 & & \\
\hline 30 & & & P06 & & \\
\hline 40 & & P18 & & $\mathrm{P} 08, \mathrm{P} 20$ & $\mathrm{P} 11, \mathrm{P} 13$ \\
\hline 50 & & & & P12 & \\
\hline 60 & & & P15 & 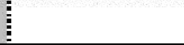 & \\
\hline
\end{tabular}

Figure 2 Main study sample frame showing each participant's characteristics, i.e. participant 01 represented as P01, woman, 20 years old, and $50 \mathrm{~kg}$.

group, most participants were working part-time (seven participants) or in full-time education (seven participants). Others were either working full-time (four participants), retired or at home not seeking work. About half the participants were owner-occupiers and the rest were renting. Located in the southeast of England, the dwellings were built in different periods, dating from 1850 to 2008. Twelve dwellings were terraced, four were within apartment blocks, three were detached and one was semi-detached. The dwelling energy efficiency ratings ranged from categories B to E, with most houses achieving a D rating (11 dwellings). Some incorporated features such as retrofitted central or communal heating systems. Only one dwelling was mechanically ventilated, all the other dwellings being naturally ventilated. Twenty participants living in 19 different dwellings were each monitored over a period of 10 consecutive days using a mixed-method approach. During the first visit, two questionnaires were completed with the householders, one focusing on socio-demographic variables, the other on thermal comfort ratings using a combination of standard questions taken from ASHRAE Standard 55-2013 (ANSI/ ASHRAE, 2013) and ISO 10551:2001 (ISO, 2001b). 
Thermal sensation was rated on a seven-point scale. Following this assessment, monitoring was carried out using an automated visual diary, wearable sensors and environmental sensors during a minimum period of 10 days. The sensors included heart rate monitors, tri-axis accelerometers, light level sensors and temperature sensors, providing measured input from which the metabolic rate and thermal insulation of clothing were ascertained when the participants were at home. The estimation methods are described below. Readings were taken over a continuous period of time throughout the day and throughout the 10 monitoring days. Finally semi-structured interviews were conducted at the end of the 10 days. The aim of this interview was to gather feedback on the monitoring methods employed and reported information on thermal discomfort responses. Open-ended questions addressing typical responses to thermal discomfort, associated thresholds and influencing factors enabled insight to be gained into the participant's relationship with their home's thermal comfort system. Content analysis was used to analyse interview transcripts in order to gain an understanding of the participants' responses to thermal discomfort and associated influencing factors. Finally, it is important to highlight that due to fieldwork constraints, this study relies on purposive sampling criteria drawn from standards rather than statistical representativeness.

This research pilot and main study used a recently developed tool allowing the daily capture of pictures from an automated wearable camera. Kelly et al. (2013) reviewed the ethical framework for automated visual diaries. The implications of their research include passive image capture, which may be interpreted as a loss of autonomy for the participant, and dissemination of information. This loss of autonomy was made explicit with the informed consent; moreover the SenseCam has a privacy button that prevents image capture for a seven-minute period. Confidentiality was ensured as the pictures 
were only accessible to the researcher and supervisors upon request. When used for presentations and publications, visual material (images captured by the SenseCam) needed additional consent from the participant; such visual material was then reviewed image by image. The pilot study and main study were registered with university data protection and approved by the research ethics committee before research commenced.

\section{Results: clothing insulation and activity level}

Participants' clothing thermal insulation $\left(\mathrm{I}_{\mathrm{cl}}\right)$ and activity levels $(\mathrm{M})$ were monitored using wearable sensors, and estimated as objective, quantitative and continuous data. Results allow for the review of the variability of $\mathrm{I}_{\mathrm{cl}}$ and $\mathrm{M}$ levels.

\section{Estimation of the clothing insulation}

To estimate the thermal insulation of the clothing $\left(\mathrm{I}_{\mathrm{cl}}\right)$, ASHRAE 55:2013, appendix B (ASHRAE, 2013), can be applied to provide a preliminary estimate of the surface temperature of clothing (equations 1 and 2). For this to apply, two conditions should be met: (1) relative air velocity $\left(\mathrm{v}_{\mathrm{a}}\right)$ should be equal to, or lower than, $0.1 \mathrm{~m} / \mathrm{s}$; and (2) participants should be sedentary:

$$
\begin{gathered}
T_{c l o}^{a}=T_{a}^{a}+\frac{\left(35.5+T_{a}\right)}{\left(3.5 \times\left(6.45 \times I_{c l}+0.1\right)\right)} \\
I_{c l}=\left[\left(\left[\left(35.5-T_{a}\right) \div\left(T_{c l o}^{a}-T_{a}^{a}\right)\right] \div 3.5\right)-0.1\right] \div 6.45
\end{gathered}
$$

Where $T_{c l o}^{a}$ is the surface temperature of clothing (Kelvin); $T_{a}^{a}$ is ambient air temperature (Kelvin); $\mathrm{T}_{\mathrm{a}}$ is the ambient air temperature (Celsius); and $\mathrm{I}_{\mathrm{cl}}$ is the clothing insulation $\left(\mathrm{m}^{2} \mathrm{~K} / \mathrm{W}\right)$ (note: $0.155 \mathrm{~m}^{2} \mathrm{~K} / \mathrm{W}=1 \mathrm{clo}$; ISO 7730:2005; ISO, 2005). Having determined the method for estimating the thermal insulation of clothing, each term of the equation was estimated as follows. First, ambient air temperature $\left(T_{a}\right)$ was 
measured using fixed HOBO U12-012 data-loggers. Three sets of four data-loggers were placed in living rooms and bedrooms, fastened to wooden poles, and positioned at 0.1, $0.6,1.1$ and $1.7 \mathrm{~m}$ from the ground to comply with the requirements set by ISO 7726:2001 (ISO, 2001a). For the purpose of the analysis, $\mathrm{T}_{\mathrm{a}}$ represents the temperature monitored in a living room experienced by standing occupants, calculated as the mean temperature over three heights: $0.1,0.6$ and $1.7 \mathrm{~m}$. As the monitoring frequency was set at five minutes, the data were resampled at a one-minute sampling rate, with each oneminute data point taking on the value of the nearest five-minute data point. Relative air velocity $\left(\mathrm{v}_{\mathrm{a}}\right)$ was measured during the first visit. For all participants, the results were equal to or below $0.1 \mathrm{~m} / \mathrm{s}$. Therefore, a relative air velocity of $0.1 \mathrm{~m} / \mathrm{s}$ was assumed for all cases on a basis that in winter the openings, such as windows, tend to remain closed (Hong, Gilbertson, Oreszczyn, Green, \& Ridley, 2009). Finally, the surface temperature of clothing $\left(\mathrm{T}_{\text {clo }}\right)$ was estimated using the wearable temperature sensor recordings. First, readings were averaged over the chosen temporal unit of analysis of one minute. Then a normalizing process was carried out to eliminate artefactual readings from the SenseCam technology that would otherwise have biased the findings. These were as follows:

Identifying and discounting the time taken for the SenseCam to reach thermal equilibrium with its environment. This is a function of the observed thermal resistance and initial temperature of the SenseCam when switched on and worn. To estimate this temperature rise time, a calibration study was undertaken and it was concluded that it takes, on average, 22 minutes from when first worn.

To fulfil the second condition of the equation it was necessary to identify when participants were sedentary in order to discount $T_{\text {clo }}$ values when participants were in motion. To do this, the mean linear acceleration (LA) over the one-minute epoch was 
estimated using the tri-axis accelerometer recordings and compared with the images of the visual diary. Results show that participants were sedentary when the measured mean LA over one minute was within the range -0.075 to $+0.075 \mathrm{~g}$ or -0.735 to $+0.735 \mathrm{~m} / \mathrm{s} 2$. Based on this observation, a data filter was written that identified Tclo when participants were sedentary.

Identifying and discounting other artefacts including the SenseCam being taken off but left switched on and SenseCam been worn under an item of clothing. The first of these was identified by using the accelerometer recordings, i.e. if $-0.01<\mathrm{LA}<+0.01 \mathrm{~g}$, then $\mathrm{T}_{\text {clo }}$ was discounted. The second was identified by using light sensor data. The efficacy of both filters was established by comparing the respective sensor data with the visual diary output.

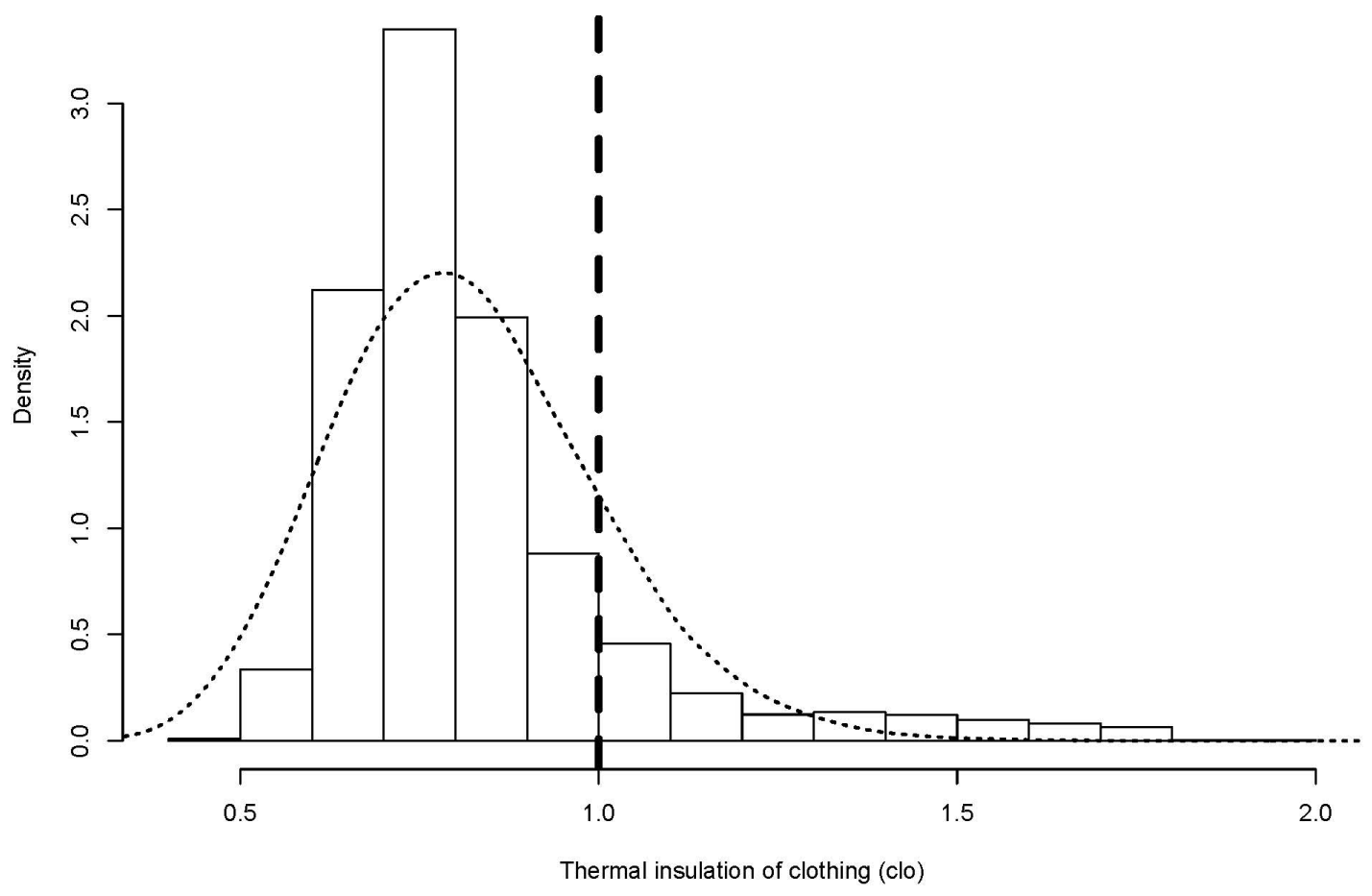

Figure 3 Density distribution of estimated thermal insulation of clothing for all participants and minimum clothing level for winter of 1 clo prescribed by EN 15251:2007 (Table A.2) 
As the monitoring occurred at the chest level of the participants, only the upper body thermal insulation level was measured. Lower body thermal insulation was taken as a constant value of 0.3 clo based on the aggregation of lower body garments including underwear, trousers or skirt, and socks. This was added to the final $\left(\mathrm{I}_{\mathrm{cl}}\right)$ value (ISO 9920:2009; ISO, 2009). The resultant $\mathrm{I}_{\mathrm{cl}}$ is summarized in Figure 3, with an indicative gamma-distribution inferred from the histogram where $\alpha=19.92$ and $\beta=24.42$. The estimated range of $0.43-1.99$ clo is within the expected standard values as described in ISO 7730:2005, 4.1 (ISO, 2005) as 0-2 clo. However the mean value of 0.82 clo is lower than the assumed winter value of 1 clo given as a constant in building energy simulation (Schiavon \& Lee, 2013) and the minimum clothing level for winter of 1 clo prescribed by EN 15251:2007, table A.2 (CEN, 2007).

\section{Estimation of the metabolic rate}

Participants' activity level was estimated from the output of the SenseCam tri-axis piezo-resistive accelerometer (Gauthier \& Shipworth, 2013). Participants' total acceleration (TA) was calculated as the normalized magnitude of the acceleration vector including the Earth's gravity (see equation 3) (Shala \& Rodriguez, 2011). Then the LA was estimated as the difference between TA and the acceleration due to gravity (see equation 4):

$$
\begin{gathered}
T A=\sqrt{\left(x^{2}+y^{2}+z^{2}\right)}=L A+g \\
L A=\sqrt{\left(x^{2}+y^{2}+z^{2}\right)}-g
\end{gathered}
$$

where TA is total acceleration $(\mathrm{m} / \mathrm{s} 2)$; LA is the linear acceleration $(\mathrm{m} / \mathrm{s} 2) ; \mathrm{x}$ is acceleration in the $\mathrm{x}$-axis $\left(\mathrm{m} / \mathrm{s}^{2}\right)$; $\mathrm{y}$ is acceleration in the $\mathrm{y}$-axis $\left(\mathrm{m} / \mathrm{s}^{2}\right) ; \mathrm{z}$ is acceleration in the $\mathrm{z}$-axis $\left(\mathrm{m} / \mathrm{s}^{2}\right)$; and $g$ is the acceleration due to gravity $\left(=9.81 \mathrm{~m} / \mathrm{s}^{2}\right)$. 
LA was then integrated over a one-second interval to estimate participants' speed. The results were then averaged over the each one-minute epoch. Assuming that participants walked between locations in their home, Ralston's equation (Ralston, 1958) may be applied:

$$
E_{w}=29+0.0053 \cdot v^{2}
$$

where $\mathrm{E}_{\mathrm{w}}$ is the energy expenditure (cal $\left./ \mathrm{min} / \mathrm{kg}\right)$; and $v$ is velocity $(\mathrm{m} / \mathrm{min})$.

After converting the variables in Ralston's equation to SI units, power was calculated and divided by the participants' body surface area using the Du Bois formula (ISO 8996:2004, 7.1.2; ISO, 2004) to estimate metabolic rate (M) in $\mathrm{W} / \mathrm{m}^{2}$ and then in met; where $1 \mathrm{met}=58.2 \mathrm{~W} / \mathrm{m}^{2}($ ISO 7730:2005; ISO, 2005). This estimation does not take into account the energy required to sit or to climb/descend stairs; such activities may be incorporated in further analysis (Rassia, Hay, Beresford \& Baker, 2009). The resultant (M) is summarized in Figure 4, with indicative gamma-distribution inferred from the histogram where $\alpha=116.79$ and $\beta=88.49$. The estimated range of $1.11-2.12$ met is within the expected standard values as described in ISO 7730:2005, 4.1, as 0.8-4 met. However the mean value of 1.32 met is higher than the activity level value of 1.2 met prescribed by EN 15251:2007, table A.2 (CEN, 2007) for residential building in living spaces. 


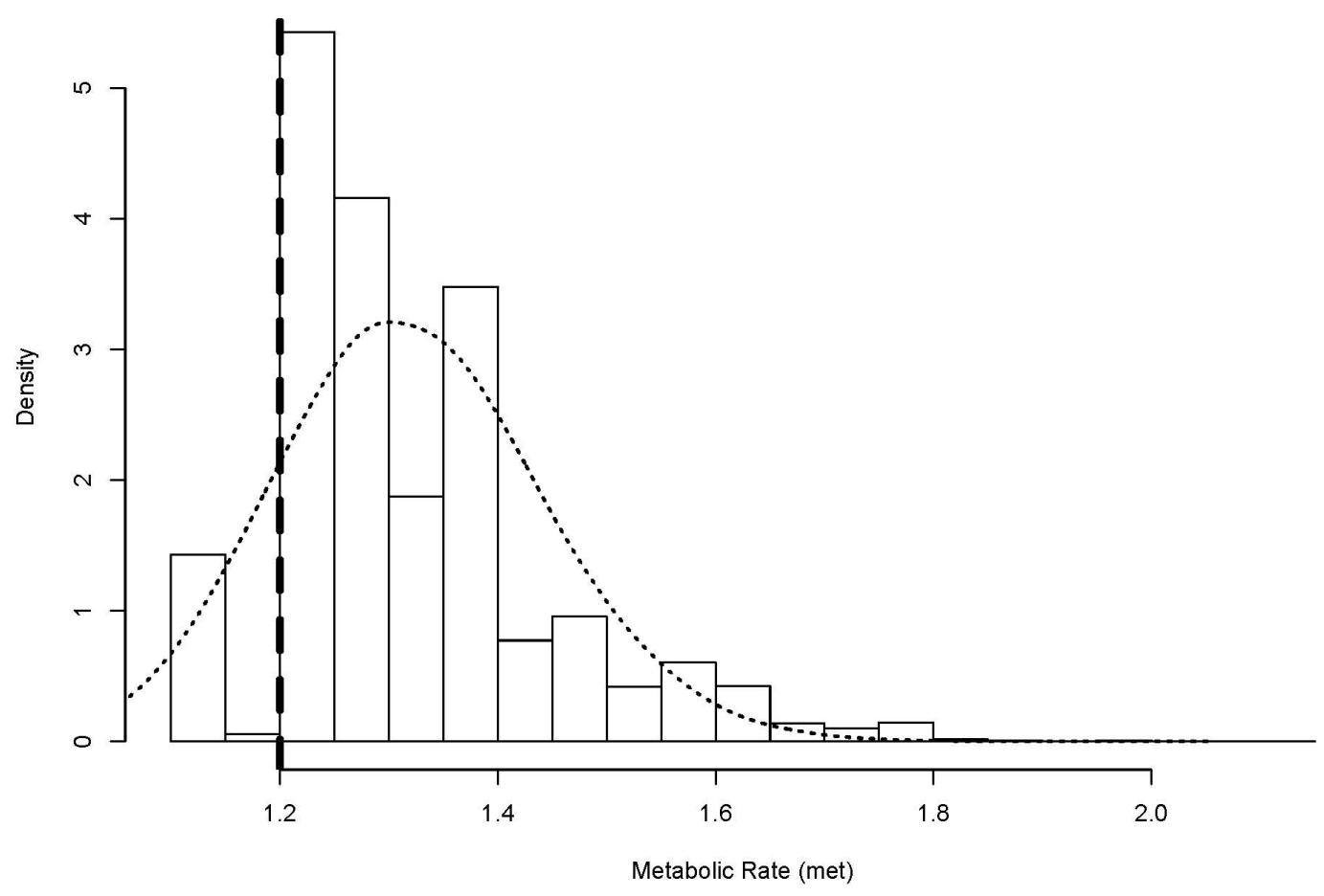

Figure 4 Density distribution of estimated metabolic rate for all participants, and activity level value of 1.2 met prescribed by EN 15251:2007 (Table A.2) for residential building in living spaces

\section{Summary}

Results from this experimental investigation generated probability distributions from the levels of metabolic rate $(\mathrm{M})$ and thermal insulation of clothing $\left(\mathrm{I}_{\mathrm{cl}}\right)$ in residential settings during the winter season. Surprisingly, the mean $\mathrm{I}_{\mathrm{cl}}$ level was $0.82 \mathrm{clo}$, which is lower than the 1 clo prescribed by EN 15251:2007 (CEN, 2007). On the other hand, the measured mean (M) was 1.32 met, which is higher than the 1.2 met also prescribed by EN 15251:2007. In summary the standard $M$ and $\mathrm{I}_{\mathrm{cl}}$ values differ from the measured values, although both are within the standard deviation of the mean as 1 clo is within $0.82 \pm 0.2$ clo and 1.2 met is within $1.32 \pm 0.13$ met. However as $\mathrm{M}$ and $\mathrm{I}_{\mathrm{cl}}$ are the most influential input variables in predictive models, these observed differences from the standard values may have a great effect on the output PMV. Using the empirical study 
monitoring results as input, different scenarios were tested. A reduction in $\mathrm{I}_{\mathrm{cl}}$ from 1 to 0.82 clo reduces the mean PMV from -0.23 to -0.51 , which is then outside the bound of category B acceptability of ISO 7730:2005 (ISO, 2005). In parallel, an increase in M from 1.20 to 1.32 met increases the mean PMV from -0.87 to -0.57 , which is still outside the bound of category B but inside the bound of category C of ISO 7730:2005. Moreover, there is a significant statistical difference in means between the two $\mathrm{M}$ scenarios $\left(M=1.2\right.$ and 1.32), and also between the two $I_{c l}$ scenarios $\left(I_{c l}=1\right.$ and 0.82$)$ (Wilcoxon signed-rank test, $\mathrm{p}<0.05$ ).

This research introduces a mixed-method framework to estimate $\mathrm{M}$ and $\mathrm{I}_{\mathrm{cl}}$ as objective, quantitative and continuous variables. Beyond reviewing the standards thresholds, these probability distributions may be used as input to building energy simulation (BES) programmes providing greater thermal variability and making simulated thermal comfort analysis more robust. Moreover, the $\mathrm{I}_{\mathrm{cl}}$ value in winter was 0.18 clo lower than the assumed typical value. This low clothing level may partially be compensated by higher observed metabolic rate. When combining these results with the environmental monitoring, the predicted mean votes are substantially below those expected in the standard model, with observed values of $-0.54 \pm 0.65$ PMV score. This analysis suggests that in order to maintain acceptable comfort levels, occupants maybe engaging in other adaptive behaviours not currently accounted for within the standard models. The second part of the research focuses on identifying any such adaptive behaviour. 


\section{Results: Monitoring people}

\section{Reported responses to thermal discomfort}

Using content analysis, the semi-structured interviews were partially transcribed focusing on the three discussions guide themes: 'typical responses', 'thresholds' and 'influencing factors' to thermal discomfort. The results of this analysis summarized in Figure 5 reveal that the most frequently reported responses to thermal discomfort for the sample group were:

- layering through putting on more clothing and increasing their thermal insulation $(47 \%)$

- interacting with the home heating system using TRVs, a room thermostat or programmers $(24 \%)$

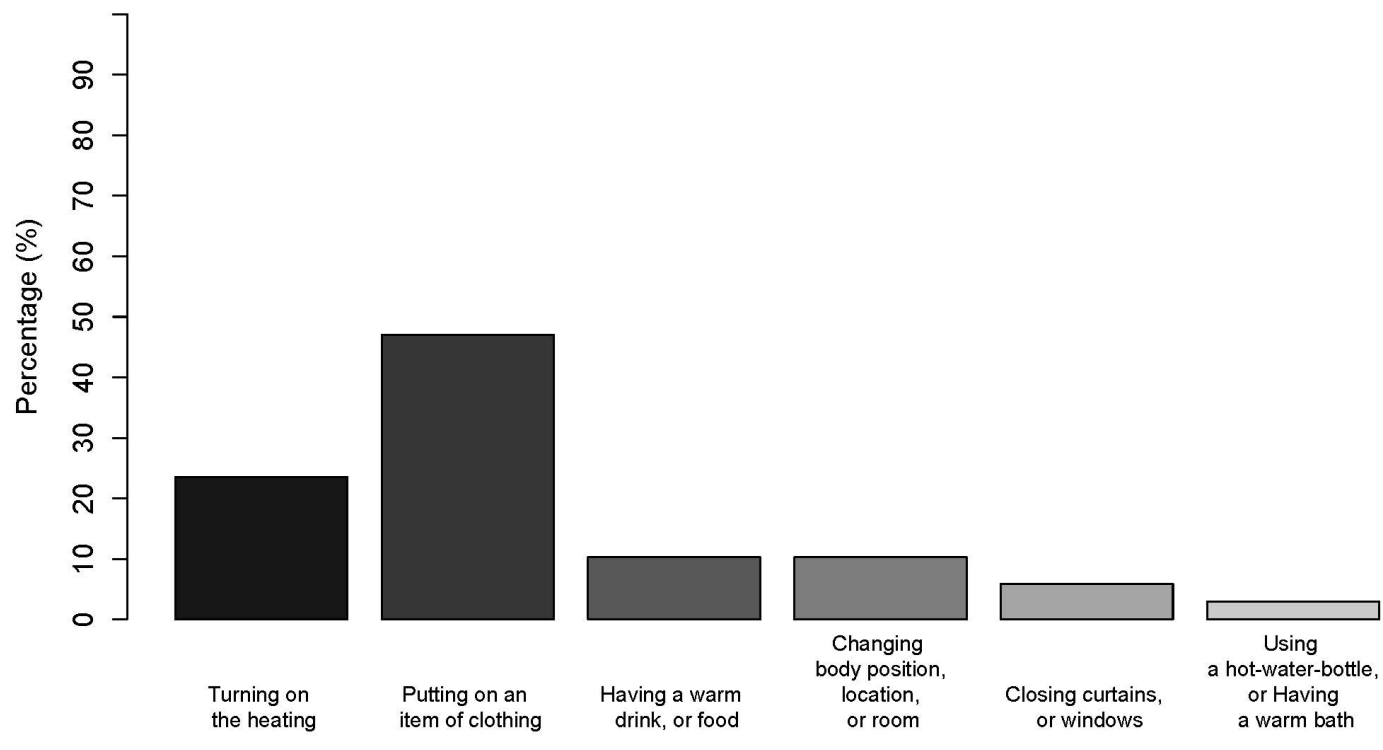

Figure 5 Semi-structured interview results - Reported responses to thermal discomfort 
Interestingly, the reported influencing factors to thermal discomfort varied greatly. In the interviews, participants suggested that a dwelling's comfort system might not be restricted to the mechanical system but include 'friends and family', 'neighbours' and 'household characteristics' as constraints or opportunities to alleviate thermal discomfort responses.

\section{Observed responses to thermal discomfort}

Through the diary collection, the SenseCam device captured automatically up to 24,306 images, and an average of 7,314 images per participant over a monitoring period of at least 10 days. This yields a very large collection of images. To process this information, automatic segmentation was used in a five-step sequence as follows:

- Formatting - After uploading the SenseCam data, the images and the output from the temperature sensor were extracted from the diary-log. This temperature entry gives an estimation of the temperature at the surface of the clothing on the participants' chests, and is referred to as $\mathrm{T}_{\text {clo }}\left({ }^{\circ} \mathrm{C}\right)$.

- Formatting $-\mathrm{T}_{\text {clo }}$ readings were then averaged over the chosen time unit of analysis set as a one-minute epoch.

- Normalizing - While reviewing $\mathrm{T}_{\text {clo }}$ time-series profiles, temperature rises were observed each time a participant put on the SenseCam. These artefacts are unwanted information contained within $\mathrm{T}_{\text {clo }}$ reading profiles. Prior to undertaking the analysis, the profiles were reviewed and these artefacts discounted; this process is called normalizing. The method consists in identifying the temperature rise-time due to the resistance of the device and/ or to changes in the environment. To do so, a software filter was written that 
identifies the lagged differences between consecutive readings. The filter boundary condition was set to $\mathrm{T}_{\text {clo }}$ being stable during a five-minute period.

- Structured query - Consecutive normalized $\mathrm{T}_{\text {clo }}$ readings were compared, and if those increased or decreased by $1{ }^{\circ} \mathrm{C}$ or more over one minute, associated images were reviewed at the time of the change occurring and at five minutes prior and posterior to the change. This was carried out to identify and validate associated behavioural responses to change in $\mathrm{T}_{\text {clo. }}$.

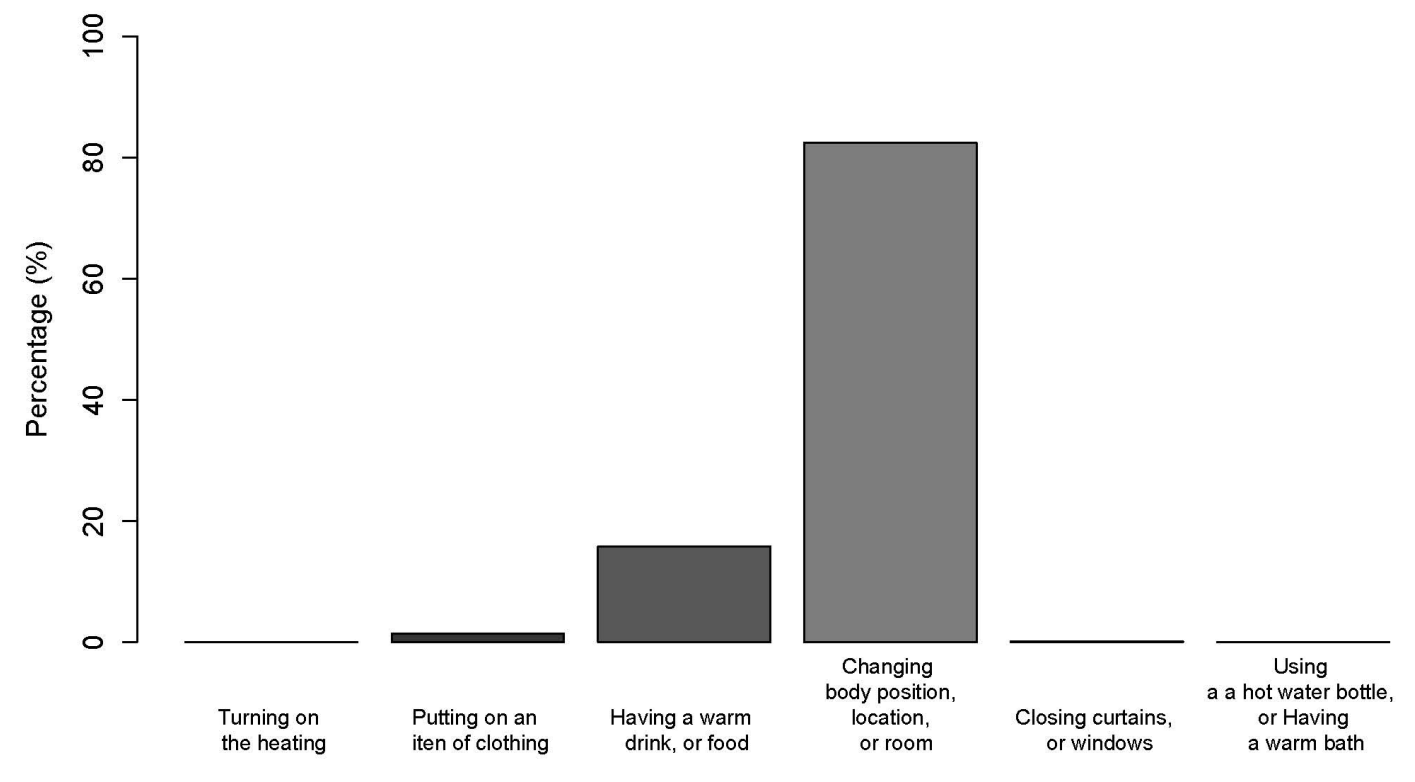

Figure 6 Automated diary results - Observed responses to thermal discomfort

This structured data-query process enabled filtering of the images to those in close proximity to observed changes in $\mathrm{T}_{\text {clo }}$. After processing, approximately $15 \%$ of the original images remained making manual inspection of the remaining images possible. Inspection of the images then allowed for identification of the reasons for changes in $\mathrm{T}_{\text {clo. }}$ Through this approach participants' responses to changes in $\mathrm{T}_{\text {clo }}$ were identified; the results are summarized in Figure 6. Interestingly, the frequencies of observed 
actions differ greatly to the reported responses. In this context, there are two important caveats that should be borne in mind in interpreting such visual diary data. Firstly, it is important to note that the localized behaviour responses observed in the SenseCam

images are not necessarily, or even predominantly, thermal discomfort responses. Occupants move, consume hot food and drink, and change clothing for many reasons, thus it is probable that the majority of the observed actions in Figure 6 associated with 'Having a warm drink or food' and 'changing body position, location or room' are not thermal discomfort responses but arise from other causes. This poses a potential threat to the internal validity of the findings. Secondly, in multiple occupant households, others may undertake thermal comfort measures on the household's behalf. These would not be recorded and could create missing data biases. To address these concerns, regression analysis between indoor monitored temperature $\left(\mathrm{T}_{\mathrm{a}}\right)$ and the most frequently reported response (clothing insulation levels) and the most frequently observed activity (motion) are presented.

\section{Monitored responses to thermal discomfort}

Predicted responses are drawn from the framework of the predictive indices. Developed from laboratory experiments in climate chambers, this framework combines knowledge of the human body physiology and of the heat transfer theories in which six variables are accounted for (ISO 7730:2005; ISO, 2005). Having estimated thermal insulation of clothing $\left(\mathrm{I}_{\mathrm{cl}}\right)$ as a quantitative, objective and continuous variable, its relationship with ambient temperature $\left(\mathrm{T}_{\mathrm{a}}\right)$ may be evaluated using regression analysis. If participants were always to adjust their thermal insulation level by adding more clothing items as a response to colder temperatures, then the correlation coefficient should be close to -1 . However the results show a very weak relationship between measured indoor air temperature and estimated clothing insulation $(\mathrm{R}=0.013, \mathrm{p}=0.067)$, which is in 


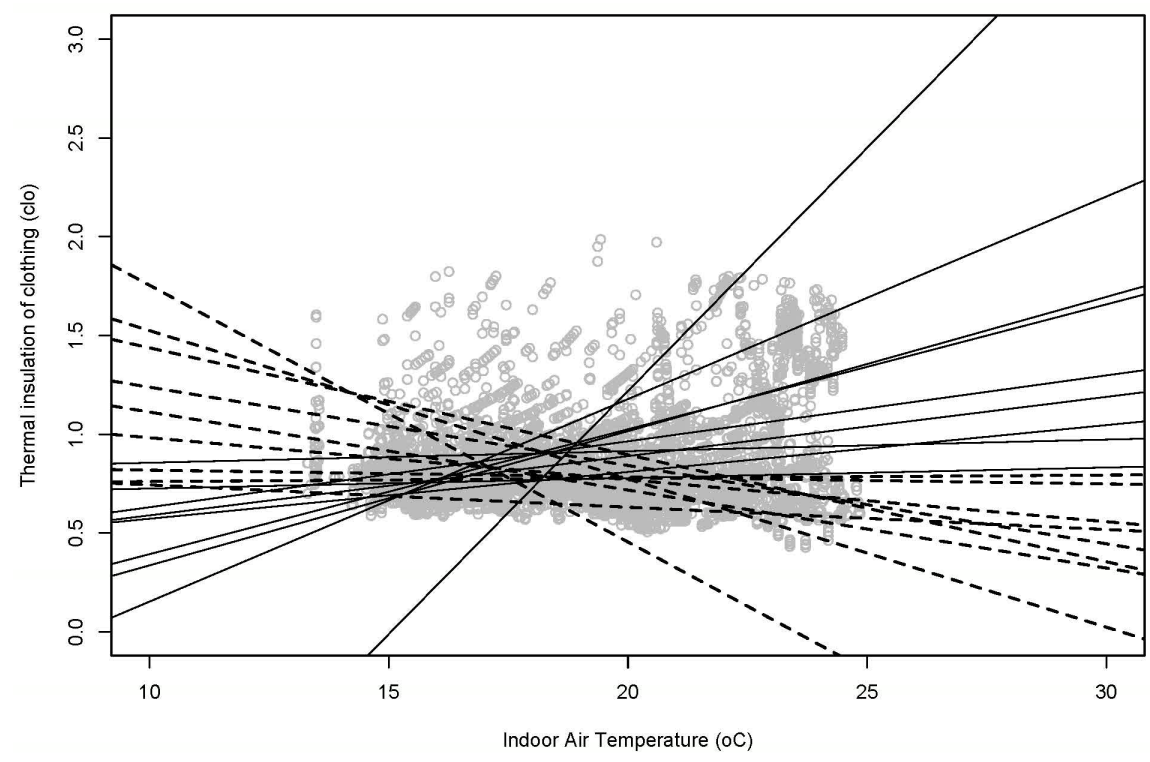

Figure 7 Monitored results - Regression analysis between monitored ambient air temperature and estimated thermal insulation of clothing for all participants with the fitted linear regression lines for each participants

Table 1 Summary statistics of the regression analysis between monitored ambient air temperature and estimated thermal insulation of clothing for each participant (note: P06 data was missing for the sensor log, and not included in the analysis)

\begin{tabular}{lccccc}
\hline Participants & $\mathbf{R}$ & Adjusted R $^{\mathbf{2}}$ & F-statistic & DF & p-value (0.05) \\
\hline P01 & 0.31 & 0.10 & 154.74 & 1419 & 0.000 \\
P02 & 0.03 & 0.03 & 81.25 & 3108 & 0.000 \\
P03 & 0.24 & 0.05 & 7.49 & 125 & 0.007 \\
P04 & $\mathbf{0 . 0 3}$ & $\mathbf{0 . 0 0}$ & $\mathbf{0 . 2 9}$ & $\mathbf{2 5 8}$ & $\mathbf{0 . 5 9 1 *}$ \\
P05 & $\mathbf{- 0 . 0 4}$ & $\mathbf{0 . 0 0}$ & $\mathbf{2 . 2 7}$ & $\mathbf{1 1 5 9}$ & $\mathbf{0 . 1 3 2 *}$ \\
P07 & -0.30 & 0.09 & 236.84 & 2462 & 0.000 \\
P08 & -0.16 & 0.02 & 5.44 & 204 & 0.021 \\
P09 & 0.37 & 0.13 & 76.50 & 495 & 0.000 \\
P10 & -0.29 & 0.08 & 245.51 & 2651 & 0.000 \\
P11 & $\mathbf{0 . 1 0}$ & $\mathbf{0 . 0 1}$ & $\mathbf{3 . 1 7}$ & $\mathbf{3 1 2}$ & $\mathbf{0 . 0 7 6}$ \\
P12 & 0.39 & 0.14 & 11.48 & 64 & 0.001 \\
P13 & -0.11 & 0.01 & 9.72 & 863 & 0.002 \\
P14 & 0.44 & 0.17 & 9.34 & 40 & 0.004 \\
P15 & 0.08 & 0.01 & 5.01 & 873 & 0.025 \\
P16 & -0.10 & 0.01 & 25.05 & 2283 & 0.000 \\
P17 & -0.24 & 0.06 & 36.69 & 592 & 0.000 \\
P18 & -0.28 & 0.08 & 78.62 & 956 & 0.000 \\
P19 & 0.46 & 0.21 & 156.19 & 585 & 0.000 \\
P20 & -0.33 & 0.10 & 13.68 & 115 & 0.003 \\
\hline
\end{tabular}


agreement with the observed response to thermal discomfort described above. However this result might be due to the analysis design as all participants were grouped in one sample. Further analysis of the data on a participant-by-participant basis revealed between-subject variations. Figure 7 and Table 1 show that half of the participants slightly increased their clothing level as the indoor air temperature decreased, however the other half decreased their clothing level as the indoor air temperature decreased. These findings establish that there is a gap between participants self-reported and sensor-observed use of clothing as a response to cold thermal discomfort. While participants reported putting on more clothes when they were cold, this was not observed for half of the participants. Therefore, this suggests that other behaviour responses may be employed, such as turning on/up the heating or localized behaviour responses.

Following this analysis, the most frequently observed activity, participants' level of motion, was estimated from the output of the SenseCam tri-axis piezoresistive accelerometer as a quantitative, objective and continuous variable. Its relationship with ambient temperature $\left(\mathrm{T}_{\mathrm{a}}\right)$ may be evaluated using regression analysis. The estimated total acceleration (TA) was then compared with the measured ambient air temperature $\left(\mathrm{T}_{\mathrm{a}}\right)$ for each participant (Figure 8 and Table 2). The overall sample size amounts to 31,540 data points and an average of 1,660 per participant. While the results show almost no relationship between activity and indoor temperature, there is a weak negative correlation suggesting that most participants tend to be slightly more active as ambient temperature gets colder. Only six participants were less active in colder temperature. This is may be due to the fact that these participants lived in relatively warmer environments and did not experience temperatures below $19^{\circ} \mathrm{C}$. These findings establish that there is limited support for increased occupant activity at lower temperatures. 


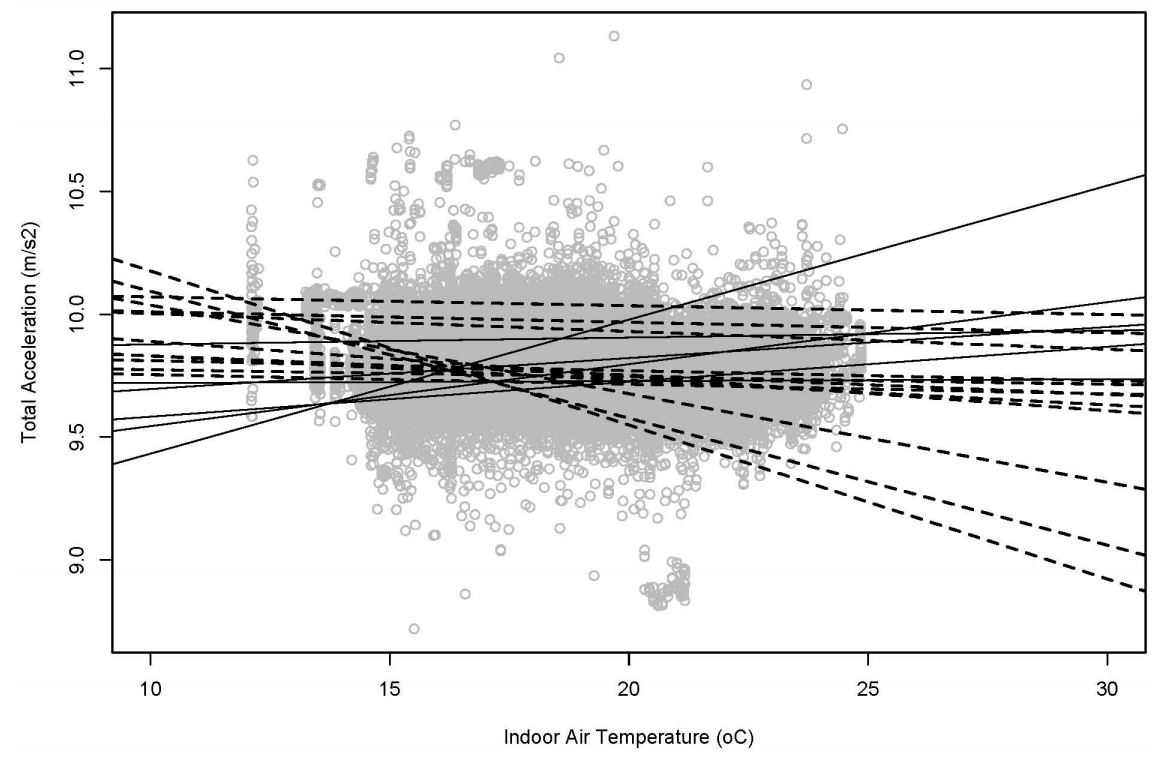

Figure 8 Monitored results - Regression analysis between monitored ambient air temperature and estimated total acceleration for all participants with the fitted linear regression lines for each participants

Table 2 Summary statistics of the regression analysis between monitored ambient air temperature and estimated total acceleration for each participant (note: P06 data was missing for the sensor log, and not included in the analysis)

\begin{tabular}{lccccc}
\hline Participants & $\mathbf{R}$ & Adjusted R $^{2}$ & F-statistic & DF & p-value (0.05) \\
\hline P01 & $\mathbf{0 . 0 4}$ & $\mathbf{0 . 0 0}$ & $\mathbf{3 . 8 5}$ & $\mathbf{2 1 1 3}$ & $\mathbf{0 . 0 5 0 *}$ \\
P02 & 0.07 & 0.00 & 24.99 & 5759 & 0.000 \\
P03 & $\mathbf{- 0 . 0 5}$ & $\mathbf{0 . 0 0}$ & $\mathbf{2 . 7 1}$ & $\mathbf{1 1 8 2}$ & $\mathbf{0 . 1 0 0 *}$ \\
P04 & -0.17 & 0.03 & 13.51 & 464 & 0.000 \\
P05 & -0.12 & 0.02 & 39.60 & 2509 & 0.000 \\
P07 & -0.04 & 0.00 & 4.32 & 3512 & 0.038 \\
P08 & 0.13 & 0.02 & 7.58 & 412 & 0.006 \\
P09 & 0.21 & 0.04 & 49.15 & 1044 & 0.000 \\
P10 & $\mathbf{0 . 0 1}$ & $\mathbf{0 . 0 0}$ & $\mathbf{0 . 1 6}$ & $\mathbf{3 6 8 0}$ & $\mathbf{0 . 6 9 1 *}$ \\
P11 & -0.10 & 0.01 & 6.31 & 676 & 0.012 \\
P12 & -0.14 & 0.02 & 22.61 & 1193 & 0.000 \\
P13 & -0.14 & 0.02 & 33.36 & 1700 & 0.000 \\
P14 & $\mathbf{- 0 . 0 5}$ & $\mathbf{0 . 0 0}$ & $\mathbf{0 . 4 6}$ & $\mathbf{2 2 0}$ & $\mathbf{0 . 4 9 6 *}$ \\
P15 & -0.44 & 0.19 & 489.17 & 2048 & 0.000 \\
P16 & -0.07 & 0.01 & 25.99 & 4653 & 0.000 \\
P17 & -0.15 & 0.02 & 33.16 & 1350 & 0.000 \\
P18 & -0.22 & 0.05 & 99.3 & 1898 & 0.000 \\
P19 & -0.06 & 0.00 & 5.74 & 1427 & 0.017 \\
P20 & 0.18 & 0.03 & 11.14 & 317 & 0.001 \\
\hline
\end{tabular}


As participants feel colder, they may chose to adjust their position, their location within the room or to change room. These form part of the localized behaviour responses.

\section{Summary}

Using content analysis of interviews and automated segmentation of visual diary data from a wearable sensor, occupant self-reported responses to thermal discomfort and observed activities correlated with thermal discomfort were compared, and the results show a marked difference between them. Most participants reported that if feeling cold they would put on an item of clothing. In contrast, correlations between clothing identified through the observation of the automated visual diary and internal temperature are very different, as participants increased clothing only in $1.4 \%$ of the observations made. This observed result is confirmed by relatively weak relationship between measured air temperature $\left(\mathrm{T}_{\mathrm{a}}\right)$ and estimated clothing insulation $\left(\mathrm{I}_{\mathrm{cl}}\right)$, which was estimated from measured temperature at the surface of the clothing on participants' chests $\left(\mathrm{T}_{\text {clo }}\right)$ and measured air temperature $\left(\mathrm{T}_{\mathrm{a}}\right)$, using ISO 7730:2005 (ISO, 2005).

These findings establish that there is a gap between reported and observed responses in the use of clothing as a response to cold thermal discomfort. Therefore, one might suggest that other behaviour responses may be employed, including turning on/up the heating or localized behavioural responses. The probability of these responses may be dependent upon personal or environmental characteristics, including the person's age, room thermal stratification amplitude and frequency, or heating system controls. 


\section{Discussion and Conclusions}

From the results of the interviews and the visual diaries, three categories of occupant behavioural response to cold thermal discomfort were identified. These categories can be viewed as a three-part framework to identify occupants' responses to cold thermal discomfort as follows:

- Increasing clothing insulation level.

- Increasing operative temperature by turning the heating system on/up.

- Increasing the frequency, duration and/or amplitude of localized behaviour responses. These include consuming warm food and/or liquids; changing body position, location within the same room or another room within the dwelling; opening and closing of curtains and/or windows; using a local device (e.g. using a hot-water bottle or having a warm bath).

These categories are then used as an analytical frame for the analysis of automated visual diaries.

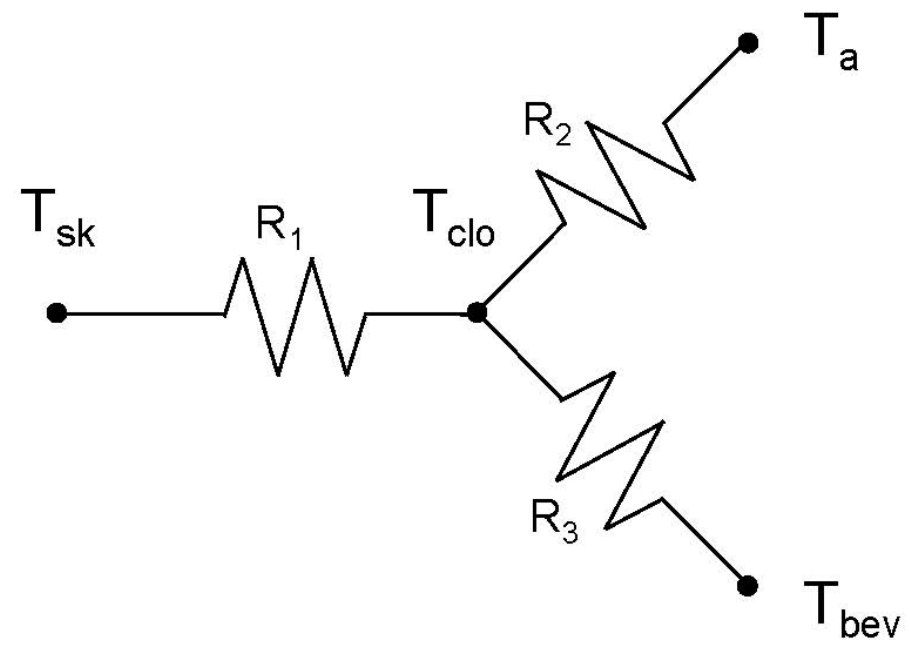

Figure 9 Diagram of heat flow around a human body - Thermal Response Model (TRM) 
From this study one might consider the heat flow around the body as a simple onedimensional system (Figure 9), where the temperature at the surface of the clothing is function of skin temperature $\left(\mathrm{T}_{\mathrm{sk}}\right)$, ambient temperature $\left(\mathrm{T}_{\mathrm{a}}\right)$, temperature derived from localized behaviour $\left(\mathrm{T}_{\text {bev }}\right)$ and the resistances in between. The reduction of the inputs and associated resistances to a single node may be represented as an application of the Millman's theorem, where:

$$
T_{\text {clo }}=\frac{\frac{T_{s k}}{R_{1}}+\frac{T_{a}}{R_{2}}+\frac{T_{b e v}}{R_{3}}}{\frac{1}{R_{1}}+\frac{1}{R_{2}}+\frac{1}{R_{3}}}
$$

Findings from this study suggest that all three resistances in the model, including R1, the resistance of clothing, remain largely constant. This leaves variation of $\mathrm{T}_{\mathrm{a}}$ (through controlling heating systems) and variation of $\mathrm{T}_{\text {bev }}$ (through a range of local behavioural responses) as the observed mechanisms for cold thermal discomfort alleviation. The review by Brager and de Dear (1998) identified this localized behaviour as part of behaviour adaptation made consciously or unconsciously by the occupants. These may be personal, technological or cultural adaptive actions and practices, and are influenced by the climate, socio-economical constraints and physical context, including the level of control a person has over the surrounding environment. In current standard predictive model, the six inputs will be affected by behavioural adaptation. For example, R1 clothing insulation $\left(\mathrm{I}_{\mathrm{cl}}\right)$ might increase if one puts on a jumper, and ambient air temperature $\left(\mathrm{T}_{\mathrm{a}}\right)$ might decrease when changing room. However the localized actions $\left(\mathrm{T}_{\text {bev }}\right)$ are not accounted for, as these might not have a physiological or physical effect but a psychological effect. Baker and Standeven's (1994) study aimed to identify these adaptive processes and to incorporate the findings into a predictive comfort model. However the results from observations and questionnaires only gathered information of the subjectively reported use of clothing and activity. The methods developed in this 
paper may be considered as an extension to Baker and Standeven's study as it allows the capture of a much wider range of adaptive behaviours and their quantification. In practice, further studies could explore different practical scenarios, including:

- Localized action: if all input variables stay constant but $T_{a}$ decreases, one response could be to 'have a warm drink', then $\mathrm{T}_{\text {bev }}$ increases and $\mathrm{T}_{\text {clo }}$ increases as a proportion of $\mathrm{T}_{\text {bev }}$ and $\mathrm{R}_{3}$.

- Heating: if all input variables stay constant but $\mathrm{T}_{\mathrm{a}}$ decreases, one response could be to 'put the heating on', then $\mathrm{T}_{\mathrm{a}}$ increases and $\mathrm{T}_{\text {clo }}$ increases as a proportion of $\mathrm{T}_{\mathrm{a}}$ and $\mathrm{R}_{2}$.

- Changing room: if all input variables stay constant but $\mathrm{T}_{\mathrm{a}}$ decreases, one response could be to 'move to a warmer room', then $\mathrm{T}_{\mathrm{a}}$ increases and $\mathrm{T}_{\text {clo }}$ increases as a proportion of $\mathrm{T}_{\mathrm{a}}$ and $\mathrm{R}_{2}$.

In summary, this study approach allows for the creation of a three-part framework mapping behaviour responses to cold sensations, consisting of (1) increasing clothing insulation level, (2) increasing operative temperature by turning the heating system on/up, and (3) increasing the frequency, duration and/or amplitude of localized behaviour responses, including, for example, warm food or drink intake, changing position, changing location within the same room or changing the room. This framework in future may be incorporated into an adaptive predictive approach (Yao, Li \& Liu, 2009) or feedback loop where the previous state of thermal comfort may be revised by current adaptive behaviour to form a future state of thermal comfort. This paper compares and contrasts occupant self-reported and observed responses to thermal discomfort and finds a marked difference between them. This led to the development of a thermal response model as a simple one-dimensional system in which 
the skin surface temperature is assumed to be constant. Future work should include heat flow within the human body. Also, this study did not consider the impact of other occupant(s) on cold thermal discomfort responses; future research may review this aspect. Finally, it is important to highlight limitations of this research that may lead to future work on the following:

- Confidentiality - Visual diary information allowed validation of the inferences made from the other sensors, and allowed for confirmation or rejection of the inferences made. In other studies collecting images may be an issue, therefore future research may develop wearable sensor kits without a camera. This would require a more thorough calibration and validation processes.

- Sample - Although the main study sample was well distributed within the sample frame, the number of participants remains relatively small. One of the main barriers remains the volume of monitoring data. The development of the automated segmentation process in this study may allow future research to recruit larger number of participants.

- Season location and setting - Methods developed in this paper were deployed in the residential sector, however it is believed that the methods could be transferable to all types of buildings. Although the study was carried out during the winter, future research may apply similar methods to gather information on people's responses to warm thermal discomfort. Additionally, this longitudinal approach may be used to investigate seasonal behavioural adaptation.

- Dynamic thermal environments - Methods developed in this paper allow the estimation of personal variables and behaviour change through time. Future research may estimate the probability of occurrence of different responses. 
To summarize, theoretically, this research introduces an extended model of discomfort response that incorporates a wider range of observed behaviours. Methodologically, this research demonstrates the efficacy of multi-method observational approaches for understanding discomfort responses. Substantively, this research highlights the importance of researchers' critical approach when evaluating occupant self-reported behaviour as this could differ from actual or observed behaviour.

\section{Funding}

This work was supported by the UK Engineering and Physical Sciences Research Council [grant number EP/H009612/1].

\section{References}

American Society of Heating, Refrigerating and Air Conditioning Engineers (ASHRAE). (2013). Standard 55-2013, thermal environmental conditions for human occupancy (ANSI approved). Atlanta, GA: ASHRAE.

ANSI/ASHRAE Standard 55. (2013). Thermal environmental conditions for human occupancy. Atlanta: American Society of Heating, Refrigerating and AirConditioning Engineers.

Baker, N., \& Standeven, M. (1994). Comfort criteria for passively cooled building a pascool task. Renewable Energy, 5(2), 977-984. doi:10.1016/09601481(94)90120-1

Baker, N., \& Standeven, M. (1995). A behavioural approach to thermal comfort assessment in naturally ventilated buildings. Proceedings of the CIBSE National Conference 1995, pp. 76-84.

Baker, N., \& Standeven, M. (1997). A behavioural approach to thermal comfort assessment. International Journal of Sustainable Energy, 19, 21-35.

Brager, G.,\&de Dear, R. (1998). Thermal adaptation in the built environment: A literature review. Energy and Buildings, 27, 83-96. doi:10.1016/S03787788(97)00053-4

Brager, G., Paliaga, G., \& de Dear, R. (2004). Operable windows, personal control, and occupant comfort - 4695 (RP-1161), 17-35. ASHRAE Transactions, 110 (Part 2). 
Bryman, A. (2004). Social research methods (2nd ed.). New York, NY: Oxford University Press.

Building Research Establishment (BRE). (2011). Reduced standard assessment procedure 2009. Watford: Garston. Retrieved August 23, 2014. http://www.bre.co.uk/filelibrary/SAP/2009/SAP-2009_9-90.pdf

Chartered Institution of Building Services Engineers (CIBSE). (2006). Degree days: Theory and application. pnTM41. London: CIBSE.

de Carli, M., Olesen, B., Zarrella, A., \& Zecchin, R. (2007). Peoples clothing behaviour according to external weather and indoor environment. Building and Environment, 42, 3965-3973. doi:10.1016/j.buildenv.2006.06.038

de Dear, R., Brager, G., \& Cooper, D. (1997). Developing an adaptive model of thermal comfort and preference. Final report. ASHRAE RP-884. Sydney, NSW: Macquarie University.

Department of Energy and Climate Change (DECC). (2013a). Digest of United Kingdom energy statistics, energy Behavioural responses to cold thermal discomfort consumption by final user - Energy supplied basis, 1970 to 2012 (DUKES 1.1.5). Technical Report. London: DECC.

Department of Energy and Climate Change (DECC). (2013b). United Kingdom housing energy fact file 2013. Technical Report. London: DECC.

European Committee for Standardization (CEN). (2007). Indoor environmental input parameters for design and assessment of energy performance of buildings addressing indoor air quality, thermal environment, lighting and acoustics. EN 15251. Technical Report. Brussels: CEN.

Gauthier, S., \& Shipworth, D. (2012). Predictive thermal comfort model: Are current field studies measuring the most influential variables? Conference proceedings: 7th Windsor Conference: The Changing Context of Comfort in an Unpredictable World, Cumberland Lodge, Windsor, UK, 12-15 April 2012. Network for Comfort and Energy Use in Buildings. London, UK.

Gauthier, S.,\&Shipworth, D. (2013). Review of methods to map people's daily activity - Application for smart homes. In A. Hakansson et al. (Eds.), Sustainability in Energy and Buildings SE - 38 (pp. 401-411). Berlin: Springer.

Heerwagen, J., \& Diamond, R. (1992). Adaptations and coping: Occupant response to discomfort in energy efficient buildings. Proceedings of 1992 Summer Study on Energy Efficiency in Buildings, 10, 83-90. 
Hodges, S., Williams, L., Berry, E., Izadi, S., Srinivasan, J., Butler, A., Smyth, G., Kapur, N.,\&Wood, K. (2006). SenseCam: A retrospective memory aid. In P. Dourish \& A. Friday (Eds.), Ubicomp 2006 LNCS, Vol. 4206, 177-193. Berlin: Springer.

Hong, S. H., Gilbertson, J., Oreszczyn, T., Green, G.,\&Ridley, I. (2009). A field study of thermal comfort in low-income dwellings in England before and after energy efficient refurbishment. Building and Environment, 44, 1228-1236. doi:10.1016/j.buildenv.2008.09.003

Hughes, M., Palmer, J., Cheng, V.,\&Shipworth, D. (2013). Sensitivity and uncertainty analysis of England's housing energy model. Building Research \& Information, 41(2), 156-167. doi:10.1080/09613218.2013.769146

Hwang, R., \& Chen, C. (2010). Field study on behaviors and adaptation of elderly people and their thermal comfort requirements in residential environments. Indoor Air, 20, 235-245. doi:10.1111/j.1600-0668.2010.00649.x

International Organization for Standardization (ISO). (2001a). BS EN ISO 7726:2001: Ergonomics of the thermal environment - Instruments for measuring physical quantities. Geneva: ISO.

International Organization for Standardization (ISO). (2001b). BS EN ISO 10551:2001: Ergonomics of the thermal environment - Assessment of the influence of the thermal environment using subjective judgement scales. Geneva: ISO.

International Organization for Standardization (ISO). (2004). BS EN ISO 8996:2004: Ergonomics of the thermal environment - Determination of metabolic rate. Geneva: ISO.

International Organization for Standardization (ISO). (2005). BS EN ISO 7730:2005: Ergonomics of the thermal environment - Analytical determination and interpretation of thermal comfort using calculation of the PMV and PPD indices and local thermal comfort criteria. Geneva: ISO.

International Organization for Standardization (ISO). (2009). BS EN ISO 9920:2009: Ergonomics of the thermal environment - Estimation of thermal insulation and water vapour resistance of a clothing ensemble (ISO 9920: 2007, Corrected version 2008-11-01). Geneva: ISO.

Karjalainen, S. (2007). Gender differences in thermal comfort and use of thermostats in everyday thermal environments. Building and Environment, 42, 1594-1603. doi:10.1016/j.buildenv.2006.01.009 
Karjalainen, S. (2009). Thermal comfort and use of thermostats in Finnish homes and offices. Building and Environment, 44, 1237-1245. doi:10.1016/j.buildenv.2008.09.002

Kelly, P., Marshall, S., Badland, H., Kerr, J., Oliver, M., Doherty, A., \& Foster, C. (2013). An ethical framework for automated, wearable cameras in health behavior research. American Journal of Preventive Medicine, 44(3), 314319.doi:10.1016/j.amepre.2012.11.006

Liu, J., Yao, R., \& McCloy, R. (2012). A method to weight three categories of adaptive thermal comfort. Energy and Buildings, 47, 312-320. doi:10.1016/j.enbuild.2011.12.007

Morgan, C., \& de Dear, R. (2003). Weather, clothing and thermal adaptation to indoor climate. Climate Research, 24, 267-284. doi:10.3354/cr024267

Ralston, H. (1958). Energy-speed relation and optimal speed during level walking. European Journal of Applied Physiology, 17, 277-283. doi:10.1007/BF00698754

Rassia, S., Hay, S., Beresford, A.,\&Baker, N. (2009). Movement dynamics in office environments. In SASBE 2009: 3rd CIB International Conference on Smart and Sustainable Built Environments, 15-19 June 2009, Delft, Netherlands.

Schiavon, S.,\&Lee, K. (2013). Influence of three dynamic predictive clothing insulation models on building energy Use, HVAC sizing and thermal comfort. University of California - Berkeley, CA: Center for the Built Environment.

Shala, U., \& Rodriguez, A. (2011). Indoor positioning using sensor-fusion in android devices (student paper). school of health and society. Kristianstad: Department Computer Science, Kristianstad University.

Silva, A., Pinho, S., Macedo, L.,\&Moulin, C. (2013). Benefits of SenseCam review on neuropsychological test performance. American Journal of Preventive Medicine, 44(3), 302-307. doi:10.1016/j.amepre.2012.11.005

UK Parliament. (2008). Climate Change Act 2008 [chapter 27]. London: HMSO.

Yao, R., Li, B., \& Liu, J. (2009). A theoretical adaptive model ofthermal comfort Adaptive predicted mean vote (aPMV). Building and Environment, 44, 2089 2096. doi:10.1016/j.buildenv.2009.02.014 